RESENHAS 


\title{
NOVAS NARRATIVAS SOBRE OS ESTADOS UNIDOS
}

\author{
Angélica Madeira
}

OliverRA, Lúcia Lippi (2001). Americanos Representações da identidade nacional no Brasil

e nos EUA. Belo Horizonte: Editora UFMG, 224p.

Há um novo interesse por um campo de estudos que, embora possa ser rastreado desde o século XIX, ganha maior visibilidade somente no cenário intelectual contemporâneo, diante da evidência da hegemonia dos Estados Unidos e de sua cultura no mundo globalizado: os estudos americanos. Tratado em si mesmo ou em trabalhos comparativos, o estudo da sociedade americana parece ser cada vez mais pertinente, para os latino-americanos em especial, à medida que vêem, com nitidez, reforçarem-se as posições de poder daquele país que possui a indústria cultural mais bem aparatada, tornando-se um centro de produção de bens e de valores mundialmente disseminados e recebidos segundo as "especificidades" das culturas que os consomem.

Artigos recentes apresentam diferentes aspectos das relações culturais entre Brasil e Estados Unidos, ora através da montagem das

\footnotetext{
Angélica Madeira é professora do Departamento de Sociologia da Universidade de Brasília, Diretora da Casa da Cultura da América Latina-UnB e professora titular do Instituto Rio Branco-MRE.
} 
expectativas dos brasileiros em relação àquele país, ora através da desmontagem das narrativas dos americanos sobre o Brasil. Exemplos do que digo são as análises sobre escritores americanos, estudos sobre políticas culturais e diálogos intelectuais que compõem a coletânea organizada por Cristina Stevens que traz o sugestivo título Quando o tio Sam pegar no tamborim: uma perspectiva transcultural do Brasil (Editora Plano, Brasília, 2001). A coletânea, de caráter eminentemente transdisciplinar, reflete com bastante nitidez as tendências do campo dos estudos literários hoje. É preciso também fazer referência à excelente monografia apresentada à disciplina Leituras Brasileiras no Instituto Rio Branco por Rodrigo Carvalho, mapeando toda a tradição americanista na América Latina e no Brasil, discutindo clássicos, delineando posições, em uma perspectiva histórica e sociologicamente orientada. A publicação de A Conquista do Oeste de Robert Wegner (Editora UFMG, 2001) discute a primeira fase da obra historiográfica de Sérgio Buarque de Holanda, o historiador das bandeiras e monções. A obra traz inúmeras precisões sobre o debate entre iberismo e americanismo e muitas comparações pertinentes entre a experiência brasileira e norte-americana. Final-mente, Americanos de Lúcia Lippi, que motivou essas breves notas. Observa-se que há todo um esforço intelectual configurado nessa densidade textual, o que leva a constatar o interesse recente e o incremento desse campo de estudos no Brasil.

A leitura do texto de Lúcia Lippi é instigante e instrutiva. Instigante por trazer à cena um tema incomum e, no entanto, tão próximo a nós. Instrutiva não só pelos argumentos que sustentam a reflexão e os conteúdos, como também, e principalmente, por ser o resultado de uma pesquisa metódica, conduzida por etapas que podem ser acompanhadas ao longo dos capítulos.

A pesquisa empreendida pela autora para realizar sua obra parte de uma revisão crítica de uma extensa bibliografia que inclui narrativas de fundação da nação, estudos comparativos ou polêmicas calorosas, como aquela que envolveu Morse e Schwartzman em torno das interpretações e soluções apresentadas para ultrapassar o atraso do Brasil.

Desde a apresentação ficamos cientes do fôlego do trabalho que parte de leituras diferenciadas, nas duas tradições, para empreender a análise comparativa. A autora assegura para si uma posição bastante 
neutra ao examinar as narrativas e os principais debates, sempre localizando-os no conjunto das forças sociais em que emergem. É bastante sóbria, mesmo ao trazer observações sobre suas experiências pessoais e impressões da sociedade americana. Ali percebe-se o cuidado de quem já analisou uma massa textual densa que contém juízos, avaliações, conselhos e prognósticos. Lucia Lippi situa-se no debate e, somente após o mapeamento do campo, busca marcar seu lugar de fala, explicitar o foco de seu olhar.

Algumas perguntas para começar. Por que tão poucos trabalhos acadêmicos comparativos sobre Brasil e USA? Por que esse desinteresse acadêmico se há tanto interesse da sociedade brasileira pelos Estados Unidos, seus valores e way of life? Em que sentido pode-se dizer que nos tornamos cada vez mais parecidos com os americanos do norte?

A não ser por poucas semelhanças inequívocas - ambos os países serem de dimensões continentais, possuírem extraordinárias riquezas naturais, serem formados por populações de imigrantes -, em tudo o mais são diferentes o Brasil e os EUA. Os processos de construção da identidade são igualmente diferenciados para brasileiros e americanos. Nos EUA, desde o período colonial, com os pioneiros do século XVII, passando pela industrialização e tensões políticas do século XIX, até a assunção do papel de líder do bloco capitalista no mundo, a partir do início da $2^{\mathrm{a}}$ Guerra Mundial, consolidam-se uma economia forte, uma política expansionista determinada e uma democracia baseada no ideário liberal republicano. O Brasil, não só pela monarquia que traz um diferencial em relação a todos os países da América do Sul e do Norte até fins do século XIX, adentra o século XX em posição economicamente subalterna, atrasado na corrida para o desenvolvimento, como país agroexportador, e sob a zona de influência dos Estados Unidos.

Apesar da forte presença da cultura norte-americana no Brasil, através dos produtos distribuídos pela indústria cultural - música, cinema, tv, moda, etc. - os estudos comparativos são relativamente escassos. Essa discrepância entre campo empírico e análise teórica é explicada pela autora pelo contexto interno da organização do campo das disciplinas nos dois países.

Na dinâmica da construção do campo intelectual, houve, segundo a análise da autora, em diálogo com Micelli, um "fechamento de 
mercado" de mão dupla: os especialistas em Brasil - brasilianistas, historiadores, antropólogos, economistas, em geral americanos - não só ocupam uma posição secundária no complexo mundo acadêmico em seu próprio país como também têm uma aceitação relativa e uma história de polêmicas com os intelectuais brasileiros. Na década de 1970, houve uma produção significativa de obras que se tornaram clássicas na área da história e da ciência política como Os militares na Política de Stephan ou Brasil: de Getúlio a Castelo de Thomas Skidmore para citar apenas dois dentre inúmeros trabalhos que consagraram seus autores.

Lucia Lippi toma as narrativas por aquilo que verdadeiramente são, isto é, construções ideológicas. Repassa a tradição historiográfica norte-americana mostrando os temas recorrentes e o papel dos pais fundadores. A diferença é marcante. Enquanto nos Estados Unidos toda a história está amplamente estudada e organizada através de grandes temas - a história política, a expansão territorial, o conflito Norte-Sul, a escravidão -, no Brasil, país de universidades tardias, a história ficará fortemente marcada pela tradição intelectual francesa e somente a partir dos anos 1960 passará a estabelecer mais conexões com o universo estadunidense, reforçadas sobretudo pelo projeto de institucionalização e de construção de um sistema de pós-graduação eficiente, financiado por fundações norte-americanas. Sob o efeito da revolução cubana, os Estados Unidos propõem uma política cultural mais agressiva - no sentido corrente que é dado a essa palavra na língua cotidiana dos americanos e no sentido ibérico, envolvendo ataque e extermínio - para a América Latina.

Os intelectuais brasileiros se relacionam com essas narrativas norte-americanas sobre o Brasil como se fossem fontes primárias de pesquisa, "versões contemporâneas das crônicas dos viajantes". Para concluir que "nessa relação de ressentimentos múltiplos não se formou uma comunidade de pares" (p.27).

Seguindo a discussão sobre o contexto interno do campo acadêmico nos dois países, a autora faz um preciso ponto de método mostrando o poder explicativo da história quando bem interrogada e desenhada por uma questão sociológica: captar as inflexões e momentos específicos, considerando mesmo as trajetórias dos principais agentes.

No Brasil, toda uma linhagem de intelectuais - Tavares Bastos, André Rebouças, Eduardo Prado, Viana Moog, Monteiro Lobato - 
formou o campo e a série discursiva que poderiam ser chamados de "americanismo". São narrativas extremamente reveladoras das imagens e miragens que os intelectuais brasileiros construíram sobre os Estados Unidos nas primeiras décadas do século XX.

Também nos outros países da América Latina, intelectuais como Sarmiento, José Martí, Rodó e Mariátegui preocuparam-se em compreender os "grandes do norte", tanto no sentido de reproduzir o sucesso do desenvolvimento norte-americano e superar nosso atraso quanto de fazer a crítica e alertar para os perigos representados pelo imperialismo. Desenvolve-se um pensamento ibero-americanista (Martí, Rodó) que defende a idéia de que não se pode abrir mão das características herdadas dos ibéricos, consideradas positivas, substituindo-as por valores que formam uma cultura extremamente individualista, racionalista e pragmática.

De fato, desde o início do século XIX, e no bojo da consolidação da Independência recente, os Estados Unidos haviam iniciado sua expansão territorial. Compras, conquistas, aquisições forçadas, guerras e anexações territoriais dotaram o país de seu próprio hemisfério, conforme frase premonitória de Thomas Jefferson; estabeleceramno como potência hegemônica do continente, não deixando dúvidas sobre a política que manteria com os países ao sul do Rio Grande (divisa com o México). Assim, desenvolveu-se um pensamento crítico e demarcador da especificidade ibérica na América Latina.

Já os "americanistas" brasileiros, de modo geral, davam um enorme peso à tradição histórica atribuindo nosso atraso e dependência ao estilo de colonização portuguesa, preocupada antes em explorar que em implantar uma civilização. Parece evidente que a modernidade e a riqueza encontram-se ao norte. Para aqueles autores, era preciso refundar o Brasil em outras bases, mais modernas; em termos econômicos, industrializar e, em termos políticos, democratizar, renegar a tradição e cultura ibéricas. No início do século XIX, a expressão "americano", muito utilizada por Alencar e pelos românticos, em geral, referia-se ao continente como um todo, afirmando o pertencimento do Brasil ao conjunto do Novo Mundo. Os Estados Unidos foram exemplo para os pensadores e reformadores sociais, como os já citados Tavares Bastos e André Rebouças, que preconizavam a terra livre e o fim da escravidão como ações conduzidas pelas elites. Estas reformas poderiam desencadear transformações políticas e sociais significativas para o 
Brasil. Com o advento da República, toda a discussão sobre o modelo político passava pela questão do americanismo. A adoção do federalismo e de toda a simbologia republicana foi fortemente inspirada pelos Estados Unidos. São Paulo foi o locus privilegiado do desenvolvimento dessa mentalidade. Ponto de partida dos bandeirantes, restando um pouco à margem do governo central, São Paulo permaneceu atrasado até o fim do ciclo das bandeiras. Só com o advento do ciclo do café é que se assiste ao triunfo do espírito pioneiro e os paulistas despontam como o povo mais industrioso, progressista, promovendo uma imigração de verdadeiros pioneiros, conforme o argumento de Viana Moog. Lúcia Lippi dedica um capítulo inteiro à idéia contida na obra Bandeirantes e Pioneiros, considerando-a um marco nos estudos comparativos entre Brasil e Estados Unidos, em diálogo com duas outras obras significativas que a antecederam: A Ilusão americana (1893) de Eduardo Prado e Pelos Estados Unidos de Oliveira Viana (1899). A primeira, imbuída de um europeísmo profundo, torna-se marco do pensamento conservador antiamericanista, enquanto a segunda defende o modelo americano, preconizando-o para o bem do progresso do Brasil. No seguimento do mesmo capítulo, repassa narrativas que tratam dessa problemática e aborda as políticas para a cultura implementadas pelos Estados Unidos na América Latina e no Brasil, a partir da Segunda Guerra Mundial. As agências criadas para a ação norte-americana ao sul do continente não só se encarregaram de estabelecer o que ficou conhecido como "a política da boa vizinhança", promovendo o intercâmbio de artistas, músicos e intelectuais, como também encarregaramse de criar uma ideologia pró-americana no Brasil, através da difusão da performance dos soldados americanos na guerra. É nesse contexto que a autora explica a emergência da obra de Moog, guiada pela pergunta, ainda pertinente na contemporaneidade, de como foi possível aos Estados Unidos se tornarem a vanguarda do capitalismo no mundo e o Brasil ter um futuro tão incerto. A resposta, sintetizada nos tipos sociais que dão título ao livro, reside não em explicações raciais, mas nos valores que formam o arcabouço das duas civilizações, os dois modelos diferenciados de ocupação do território, acentuando a importância da geografia e do clima assim como dos padrões de colonização. O pioneiro puritano rompeu com a Europa e com o passado; o português, mesmo se nascido no Brasil, mantinha o Velho Mundo como referência. Muitas outras diferenças permeiam a análise compa- 
rativa de Viana Moog, da relação com o trabalho à caução da religião, à relação com o dinheiro ao qual os americanos atribuem um valor quase místico. Essas diferenças acentuaram-se, segundo o autor, a partir de meados do século XIX, e tenderiam a se acirrarem, apesar das mudanças históricas em curso no seu tempo.

No capítulo em que trata das representações da identidade nacional dos Estados Unidos, Lúcia irá estudar um dos autores responsáveis pela elaboração de narrativas fundadoras: Jackson Turner, o historiador das fronteiras norte-americanas do final do século XIX. Sua explicação da história do expansionismo dos Estados Unidos corrobora a famosa frase de Meining, citada pela autora, que diz que "os Estados Unidos da América foram um experimento geopolítico”. A expansão ocorrida no século XIX encontra sempre sua justificativa na necessidade de manter o equilíbrio da federação. O capítulo aborda ainda a imagem criada por Jefferson de uma república democrática em que o território e a nação imaginada se identificam por uma espécie de "destino manifesto", conforme expressão cunhada por O'Sullivan em meados do século XIX, justificando a ocupação das terras indígenas e mexicanas para que não se detivesse o progresso da nação. A geografia e a história oferecem uma forte base para a construção da identidade nacional norte-americana, portadoras que são de valores políticos e ideológicos.

Na seqüência, a análise da obra de Turner volta-se para seu teor mítico e religioso, focando a história americana como um desdobramento da vontade de Deus e da renovação da virtude.

Outro importante construtor de mito destacado pela autora é Roosevelt que, em fins do século XIX, defendia os pontos que considerava fundamentais para a continuidade do progresso da América: a república, o desenvolvimento de virtudes marciais, a religião que garantia o amor ao trabalho e o esforço produtivo e, finalmente, a procriação para que haja herdeiros para as terras semeadas. Após dois anos de permanência em seu rancho em Dakota, Roosevelt volta para Nova Iorque e inicia a publicação de uma longa lista de obras sobre a conquista e a vida no Oeste, tendo como palco o mundo agrário e como personagem exemplar o fazendeiro.

Voltando às primeiras décadas do século XX, no Brasil, Monteiro Lobato será um grande admirador dos Estados Unidos, principalmente no que se refere à livre-iniciativa, vista como a antítese de um modelo 
político de um Estado cada vez mais forte e interventor na economia, como foi o primeiro governo Vargas (1930-45). Lobato combateu o parasitismo social, o protecionismo, e valorizou a iniciativa individual em uma clara defesa do fordismo como modelo econômico e de controle social. Entusiasta da experiência norte-americana, crê que o Brasil poderá se equiparar aos Estados Unidos "em grandeza, cultura, eficiência e poder, se tomarmos pelos mesmos caminhos". Isto é: explorando o subsolo - ferro e petróleo, alavancas do progresso e da modernização - e vencendo o parasitismo social e as doenças que assolavam o homem do campo.

É esse o Espelho de Próspero no qual - e equivocamente, segundo Richard Morse - o Brasil pretende se mirar. A obra que traz esse título põe em evidência o antigo contraste entre as duas civilizações: a ibero-americana e a anglo-americana. Não o move o desejo de exaltar os valores americanos, mas sim o de mostrar seu desencanto para com aqueles mesmos valores, em que pese posição ambígua do autor no contexto acadêmico estadunidense.

Não poderia aqui reproduzir os termos das polêmicas que o ensaio de Morse suscitou. Intelectuais defensores do conhecimento científico baseado em métodos objetivos fizeram fortes e pesadas críticas às idéias do brasilianista, argumentando, como Simon Schwartzman, como aquelas idéias eram equivocadas e como poderiam trazer consequiências perniciosas ao deixarem entender que:

O liberalismo, a democracia representativa, o racionalismo, o empirismo científico e o pragmatismo não só seriam incompatíveis com a realidade mais profunda da América ibérica, como também marcariam a decadência e a falta de sentido da sociedade capitalista e burguesa. (Lippi, p.55)

A polêmica entre o brasilianista americano e o cientista político brasileiro prossegue trazendo à tona as mais marcantes dicotomias entre as duas culturas, principalmente no que se refere ao comportamento político, e deixa clara a construção ideológica de Morse, através de uma retórica feita de ironia, nem sempre fina, e de erudição. O discurso reportado de Lúcia Lippi, que se recusa a tomar partido na polêmica, separando o objetivo de convencimento do conhecimento, parece apresentar um bom argumento em defesa do brasilianista americano. Ancora a narrativa Morse na melhor tradição 
literária, inserindo-a em uma série que passa por Marco Polo, Mandeville e Rousseau, mostrando o quanto o encantar-se com outras culturas faz parte do imaginário ocidental.

Na esteira de Roberto da Matta, e discutindo suas idéias, o livro traz um capítulo sobre as comemorações cívicas e cívico-religiosas, detendo-se na análise do significado simbólico do Dia da Ação de Graças, verdadeiro mito de fundação, em que se dramatiza a ruptura com a Europa e a inclusão dos nativos na construção da nova nação.

Mas talvez o ponto mais alto da obra Americanos seja os capítulos que tratam da questão do espaço geográfico, base comum da construção da nação. Da hipótese original - a força da geografia na construção do imaginário da nacionalidade nos dois países - à discussão sobre as categorias de fronteira e de sertão, Lúcia Lippi vai mostrando as numerosas representações, desde o romantismo até a modernidade em torno do interior do Brasil, o mito e seus desdobramentos no sertanejo idealizado de Alencar e de Taunay ou nos retardatários de Euclides e de Lobato, ou ainda na ambivalente figura do bandeirante ousado que amplia as fronteiras da nação. Para o estudo da construção da nacionalidade americana a autora se baseará em Turner e Roosevelt. Investimento intelectual sui generis já que não é comum em nosso universo intelectual estudar a história dos Estados Unidos e investimento crítico de desmonte das ideologias ao tomar como superfície de análise as narrativas dos pais fundadores.

Este estudo comparativo é revelador dos diferentes éthos que têm vigência nas duas sociedade, discutidos através dos tipos ideais, o puritano e o ibérico. Ao longo do livro, percebe-se a preocupação em pontuar a presença da religião na organização de ambas sociedades, tanto da sociedade civil norte-americana, através das benevolents societies e outras instituições, o que mostra o papel racionalizador do Protestantismo e seu peso na orientação das condutas, quanto das formas de organização das sociedades ibéricas. Mesmo que nem sempre de maneira explícita, a questão do iberismo permanece como contraste à análise dos americanos do norte.

Estudar as representações que os intelectuais constroem sobre a identidade de suas nações conduz inevitavelmente à qualificação das condições de produção daquelas narrativas e imagens, contextualizando-as, trazendo à tona as motivações e os jogos de força que as impulsionaram. Só compreendendo os modelos que subjazem às ações 
é possível uma discussão consistente sobre os discursos e as ideologias. A recente questão do multiculturalismo, entendida a partir dos modelos culturais vigentes nos dois países, merece uma das reflexões mais lúcidas da autora ao evidenciar os padrões diferenciados de relacionamento com o imigrante, um padrão segregacionista nos Estados Unidos e um assimilacionista no Brasil. Não se trata de julgar ou avaliar mas de constatar a diferença das gramáticas que regem as relações interétnicas e interraciais nos dois países. Tudo isso desfavorece uma adaptação tout court do modelo multicultural norte-americano para produzir as novas identidades sociais. Na América Latina, continua a ter força produtiva a valorização da mestiçagem e das relações personalizadas. O movimento das minorias nos Estados Unidos emerge em concomitância ao deslocamento de interesses e à reestruturação das disciplinas acadêmicas.

A situação da universidade americana vem sendo alterada significativamente há duas ou três décadas. A partir dos anos 1980, revigorouse e politizou-se o debate teórico; as universidades passaram a receber um número significativo de intelectuais de vários países da América Latina assim como levas de estudantes de origem latino-americana, promovendo a emergência de uma geração de intelectuais e artistas chicanos. O crescimento do interesse pela América Latina, pela especificidade de sua cultura, diante da evidência de sua presença nas metrópoles e mesmo do predomínio em muitas regiões dos Estados Unidos, pode ser comprovado pelo grande números de departamentos, associações, congressos, um grande incremento e uma verdadeira institucionalização do campo.

Os estudos sobre Brasil continuarão a ser uma fração dos estudos latino-americanos que ganham em amplitude e interesse devido à diáspora latina no norte. Identidades culturais dúbias ou híbridas contribuem para produzir um novo estilo de intelectual que fala sobre a América Latina com a dupla autoridade: a de possuir o background latino e a de ocupar um lugar de poder em relação à América Latina, a academia americana. Agora não são mais os brasileiros e latinoamericanos que vão aos Estados Unidos aprender como devem estudar. Nos departamentos de espanhol ou nos estudos de área, o interesse pela América Latina alastra-se também devido à nova consciência do campo estratégico que o sul do continente representa para os Estados Unidos. As disciplinas se organizam e os artistas 
expressam suas dúvidas, descaminhos, e deixam falar, em sua linguagem híbrida, aquilo que a ideologia esconde.

Se aqueles debates e polêmicas sobre identidade fizeram enorme sentido nas primeiras décadas do século XX, a partir dos anos 60 do mesmo século, reciclou-se um termo antigo mas que se aplicava bem ao estilo de mando assumido pelos Estados Unidos: o imperialismo. Hoje sua lógica é outra; não mais guerras localizadas para delimitar zonas de influência, não mais territórios geográficos e sim territórios imaginários, que garantem um imenso mercado consumidor para sua eficiente indústria cultural. Exportar não somente produtos mas o estilo de vida inteiro, os hábitos, os valores que se espalham no tecido social através de uma lógica bastante sutil e imanente à sociedade de consumo. De fato, o consumo por si só, como prática cultural, estabelece uma forma de controle que prescinde de outras mediações institucionais. O modelo de sociedade baseado no consumo torna possível a criação de um consenso capaz de moldar grandes massas e, ao mesmo tempo, articular as heterogeneidades sociais, as minorias.

Nosso papel, ao entrar nesse debate, é o de constatar sua relevância e tentar trazer mais clareza sobre um campo em transformação. De fato, há todo um conjunto de obras recentes que tomam a cultura dos americanos como tema central; algumas delas, escritas pelos próprios americanos, trazem uma visão bastante crítica daquilo que chamam "a cegueira do centro" (Jameson) ou a sociedade da "alienação autônoma" (Negri e Hardt).

A sociedade de consumo vê sobrepor-se a esfera da cultura à da economia, e essa desdiferenciação das esferas pode ser tomada como um poderoso sintoma da superação da modernidade, tal como foi concebida por Weber.

Há ainda narrativas muitos mais radicais em suas críticas às formas de dominação dos Estados Unidos, como as de Noam Chomsky, e outras, no extremo oposto, como as de Huntchington, que poderiam ser tomadas como parâmetro e lições de método de como se dá a fabricação desse novo momento da história da cultura mundial globalizada. Basta rastreá-las para compreendermos o slogan de Barbara Kruger: You do history while you do business. 